\title{
Commentary: Toward safer aortic surgery: Monitoring spinal cord perfusion with near-infrared spectroscopy
}

\author{
Juan A. Crestanello, MD
}

\author{
From the Department of Cardiovascular Surgery, Mayo Clinic, Rochester, Minn. \\ Disclosures: Author has nothing to disclose with regard to commercial support. \\ Received for publication Dec 9, 2018; accepted for publication Dec 10, 2018; available ahead of print Jan 11, \\ 2019. \\ Address for reprints: Juan A. Crestanello, MD, Department of Cardiovascular Surgery, Mayo Clinic, 200 First St \\ SW, Rochester, MN 55905 (E-mail: crestanello.juan@mayo.edu). \\ J Thorac Cardiovasc Surg 2019;158:165-6 \\ $0022-5223 / \$ 36.00$ \\ Copyright (C) 2018 by The American Association for Thoracic Surgery \\ https://doi.org/10.1016/j.jtcvs.2018.12.028
}

Spinal cord perfusion is provided by segmental arteries that originate from the vertebral, intercostal, lumbar, and hypogastric arteries. This segmental origin of spinal perfusion is supplemented by an extensive intraspinal and paraspinal anastomotic network that provides longitudinal collateral circulation among the horizontally distributed segmental arteries. However, this longitudinal anastomotic network is usually insufficient to maintain spinal perfusion when acute or extensive interruption of the segmental system occurs. The dorsal branches of the intercostal and lumbar arteries provide the segmental blood supply to the spinal cord through the radiculo-medullary arteries and to the paravertebral muscles (Figure 1). Interruption of the blood supply to an intercostal or lumbar artery results in decreased blood flow not only to the spinal cord but also to the paravertebral muscles. Therefore, monitoring perfusion to the paravertebral muscles provides an indirect evaluation of the spinal cord perfusion. Because interruption of the blood supply to the lower intercostals and upper lumbar arteries is associated with the higher rate of spinal ischemia, evaluating the perfusion of the paravertebral muscles at those levels will likely be more clinically significant.

In this issue of the Journal, von Aspern and colleagues ${ }^{1}$ expand on their previous work using near-infrared spectroscopy (NIRS) to noninvasively, in real time, and continuously monitor blood flow/oxygenation to the lumbar paravertebral muscles as an indicator of blood flow to the spinal cord. ${ }^{1-5}$ They called it monitoring of the "collateral network" (paravertebral muscles perfusion). ${ }^{2}$ In a swine model, the authors simulated the spinal ischemia that would occur with an extent II thoracoabdominal aorta replacement with and without reimplantation of the lower intercostalupper lumbar arteries. The authors found that NIRS measurements correlate with the degree of spinal ischemia and neurologic outcomes. NIRS signal decreased early after artery occlusion and started to recover within 1 hour after occlusion. Persistent paraplegia was associated with more

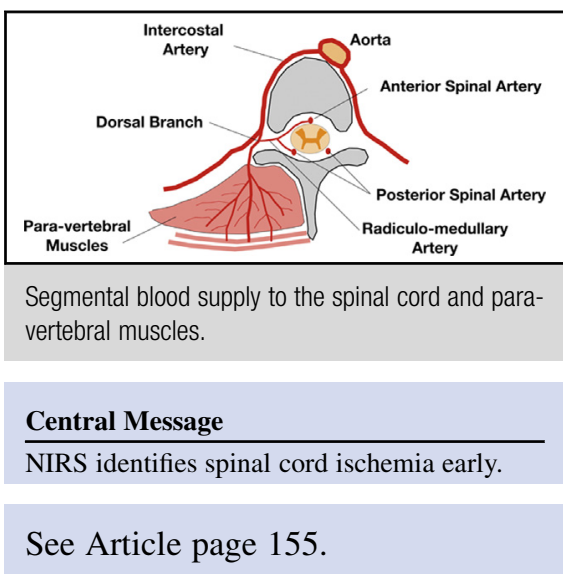

severe initial decrease and delayed and less than complete recovery of the NIRS signal. In addition, NIRS levels were directly correlated with the severity of the neurologic impairment; the lower the NIRS reading, the worse the neurologic outcome. Finally, as expected, animals with more severe neurologic impairment had more significant histologic changes in the spinal cord.

The research by von Aspern and colleagues ${ }^{1}$ on the use of NIRS for the noninvasive continuous monitoring of spinal ischemia contributes to increase the safety of aortic surgery and endovascular procedures by identifying spinal ischemia early, allowing for early intervention, and hopefully preventing its devastating consequences. The utility of this monitoring technique should be further studied in clinical trials and potentially used during not only the surgical/endovascular procedures but also the early postoperative period.

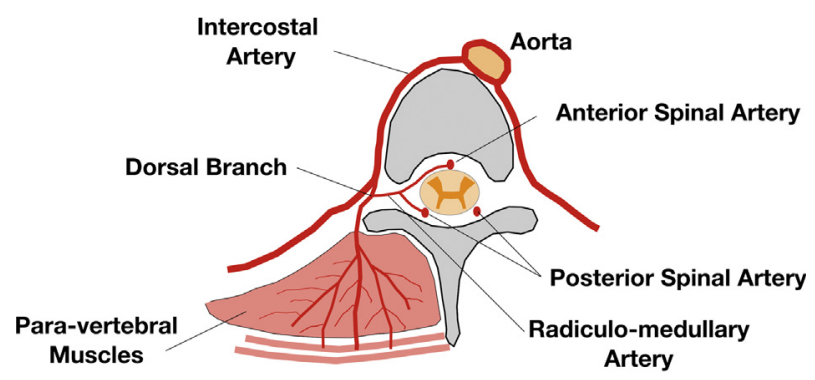

FIGURE 1. Diagram demonstrating the segmental blood supply to the spinal cord and paravertebral muscles. Note the common origin of the radiculo-medullary artery and the branches for the paravertebral muscles. This common origin provides the anatomic foundation for NIRS monitoring of the paravertebral muscles as an indicator of spinal cord ischemia. 


\section{References}

1. von Aspern K, Haunschild, Ziemann M, Misfeld M, Mohr F, Borger MA, et al. Evaluation of collateral network near-infrared spectroscopy during and after segmental artery occlusion in a chronic large animal model. J Thorac Cardivasc Surg. 2019;158:155-64.e5.

2. Etz CD, Kari FA, Mueller CS, Brenner RM, Lin HM, Griepp RB. The collateral network concept: remodeling of the arterial collateral network after experimental segmental artery sacrifice. J Thorac Cardiovasc Surg. 2011;141:1029-36.

3. von Aspern K, Haunschild J, Hoyer A, Luehr M, Bakhtiary F, Misfeld M, et al Non-invasive spinal cord oxygenation monitoring: validating collateral network near-infrared spectroscopy for thoracoabdominal aortic aneurysm repair. Eur $J$ Cardiothorac Surg. 2016;50:675-83.

4. Von Aspern K, Luehr M, Mohr FW, Etz CD. Spinal cord protection in openand endovascular thoracoabdominal aortic aneurysm repair: critical review of current concepts and future perspectives. J Cardiovasc Surg (Torino). 2015;56: 745-9.

5. Etz CD, von Aspern K, Gudehus S, Luehr M, Girrbach F, Ender J, et al. Nearinfrared spectroscopy monitoring of the collateral network prior to, during, and after thoracoabdominal aortic repair: a pilot study. Eur J Vasc Endovasc Surg. 2013;46:651-6. 